\title{
Influence of aggregate size and free water on the dynamic behaviour of concrete subjected to impact loading
}

\author{
B. Erzar ${ }^{1}$, P. Forquin ${ }^{1, \mathrm{a}}$, C. Pontiroli ${ }^{2}$, and E. Buzaud ${ }^{2}$ \\ ${ }^{1}$ Laboratoire de Physique et Mécanique des Matériaux, Université Paul Verlaine - Metz, 57045 Metz \\ Cedex 01, France \\ ${ }^{2}$ Centre d'Etudes de Gramat, Commissariat à l'Energie Atomique, 46500 Gramat, France
}

\begin{abstract}
Concrete is a material widely used in civil en gineering. Thus the knowledge of its mech anical behaviour is a major safety issue to evaluate the ability of a stru cture to resist to an intense dynamic loading. In this study, two experimental techniques have been applied to a micro-concrete and a co mmon concrete to assess the influence of the aggregate size on the dynamic re sponse. First, spalling tests on dry and wet specimens have been performed to characterize the tensile strength of concrete at strain rates in the range $30-150 / \mathrm{s}$. Then, e dge-on i mpact tests in sarcophagus configuration have be en conducted. The cracking pattern of the micro-concrete and the concrete plates in wet and dry conditions have been compared to appraise the influence of aggregate size and free water on the damaging process.
\end{abstract}

\section{Introduction}

Although concrete is widely used for construction all around the world, its mechanical behaviour is not well understood in dynamic conditions. The tensile properties of concretes constitute generally the main weakness of these materials. Toutlemonde [1] perf ormed direct te nsile te sts on different concretes at relatively low strain rates (up to $1 / \mathrm{s}$ ). The influence of aggregate size and the free water were particularly investigated. The results showed that, in this range of load ing rate, the aggregate size presents a limited influence on the tensile strength while the free water appeared as a prominent parameter. An en hancement of tens ile stre ngth of $3 \mathrm{MPa}$ w as observ ed bet ween quasi-static value (obtained at $1 \mathrm{e}-5 / \mathrm{s}$ ) and $\mathrm{t}$ he dy namic on e (at ab out 1/s) for wet speci mens while dr y co ncrete samples present a limited improvement of about $1 \mathrm{MPa}$ in the same range of loading rate. At higher rates of strain, spalli ng te sts are suitable to identify the dy namic strength of co ncrete [2 -4]. Klepaczko and B rara [2 ] a dapted th e Ho pkinson bars ap paratus to test co ncrete in $\mathrm{d}$ ynamic conditions by re moving the ou tput bar. Using th is tech nique, several experi mental data $h$ ave been gathered on wet and dry specimens. Unfortunately, no measurement was performed directly on the specimen. Based on the same principle, Schuler et al. [3] used an acceleration sensor placed on the rear face of the specimen to get the free surface velocity, and computed the tensile strength from this signal. W eerheijm and $\mathrm{Va} \mathrm{n}$ Doormaal [ 4] realised e xperiments o $\mathrm{n}$ co ncrete using a si milar configuration. They $\mathrm{u}$ sed str ain $\mathrm{g}$ auges on the tested concrete specimen to obtai $\mathrm{n}$ local data

\footnotetext{
a e-mail : forquin@univ-metz.fr
}

This is an Open Access article distributed under the terms of the Creative Commons Attribution-Noncommercial License 3.0, which permits unrestricted use, distribution, and reproduction in any noncommercial medium, provided the original work is properly cited. 
concerning the loading field that allowed deducing the tensile strength. In this study, two concretes are compared: the MB50 micro-concrete with a maximum aggregate size of $2 \mathrm{~mm}$ and the R30 A7 concrete, a co mmon concrete with a maximum grain size of $8 \mathrm{~mm}$. In the first part, these materials are presen ted and th eir $\mathrm{m}$ ain $\mathrm{m}$ echanical properties are $\mathrm{g}$ iven. A seco nd part is ded icated to th $\mathrm{e}$ experimental ca mpaign of spalling test s perf ormed to $i$ nvestigate $t$ he sensitivity of th e tensile strength to the strain rate. In the third part, another technique is applied to investigate the response of a concrete targ et to a ballisti c impact: the so-called edge-on impact tests have been conducted on both co ncretes. Consequently, by crossc hecking all experimental data, the influence of ag gregate size and free water on the dynamic response of concrete has been appraised.

\section{Tested concretes}

\subsection{The MB50 micro-concrete}

Due to their macroscopic heterogeneities, concretes are generally difficult to test in dynamic conditions. The MB50 micro-concrete has been designed to be representative of a standard concrete with a small maximum aggregate size $(2 \mathrm{~mm})$ : the distribution of aggregates and the water to cement ratio are similar to a common concrete. This particularity allows reducing the tested volume which is convenient for laboratory testing. Its main properties are gathered in Table 1. Several experimental data are available for this material in direct tension [1], in bending [5] or in splitting [6]. Moreover, its compressive behaviour has been studied in simple compression [7] and under high confining pressure [8-10].

\subsection{The R30A7 concrete}

The R30A7 concrete has been designed to be representative of a standard concrete. Oppositely to the MB50 micro-concrete, bigger inclusions are included: its maximum aggregate size is $8 \mathrm{~mm}$. Its behavior has already been studied in confined compression [11] and quasi-oedometric tests [12]. Its composition and its main mechanical properties are reported in Table 1.

\subsection{Tested specimens}

The specimens used for spalling tests are c ylinders $46 \mathrm{~mm}$ in dia meter and 120 or $140 \mathrm{~mm}$ in length. T o perf orm ed ge-on impact test s plates of $200 \times 120 \times 15 \mathrm{~mm}^{3} \mathrm{w}$ ere u sed. They were all obtained from large blocks $\left(30 \times 30 \times 20 \mathrm{~cm}^{3}\right) \mathrm{b}$ y d rilling, $\mathrm{c}$ utting and $\mathrm{g}$ rounding. Af ter th $\mathrm{e}$ machining processes, they have been stored in water saturated by lime to a void the dis solution of portlandite. On the one hand, sat urated specimens were pi cked up from water le ss than one hour before testing and re gularly re-hydrated during their preparation. On the other hand, a sec ond set of specimen was des iccated at $60^{\circ} \mathrm{C}$ du ring several weeks. The los s of water was reg ularly checked until the mass of the specimen stabilized.

\section{Dynamic tensile testing: spalling experiments}

To test the concrete at high strain rates, one can conduct spalling tests. During this experiment, the impact of a projectile generates a compressive pulse propagating through an instrumented bar (cf. Fig. 1). A part of the wave is trans mitted to the concrete cylinder while the other part is ref lected back in the bar. The compressive loading propag ates through the specimen on which several strain gauges are placed. When it reaches the free surface, the incident compressive pulse is reflected into a tensile wave propag ating in the oppos ite direction. A tensile field appears along the secimen leading to its dynamic failure. 
Table 1. Composition and main mechanical properties of the MB50 and the R30A7 concrete.

\begin{tabular}{|ccc|}
\hline Composition & MB50 [1] & R30A7 [11] \\
\hline Aggregates $\left(\mathrm{kg} / \mathrm{m}^{3}\right)$ & 0 & 1008 \\
Sand $\left(\mathrm{kg} / \mathrm{m}^{3}\right)$ & 1783 & 838 \\
Cement $\left(\mathrm{kg} / \mathrm{m}^{3}\right)$ & 400 & 263 \\
Water $\left(\mathrm{kg} / \mathrm{m}^{3}\right)$ & 200 & 169 \\
Admixture $\left(\mathrm{kg} / \mathrm{m}^{3}\right)$ & 12 & 0 \\
Water $/$ Cement & 0.5 & 0.64 \\
Maximum aggregate size (mm) & 2 & 8 \\
\hline Main mechanical properties & MB50 [6] & R30A7 [11,12] \\
\hline Compressive Strength (MPa) & 70 & 29 \\
Tensile Strength (MPa) & 3 & 3.6 \\
\hline
\end{tabular}

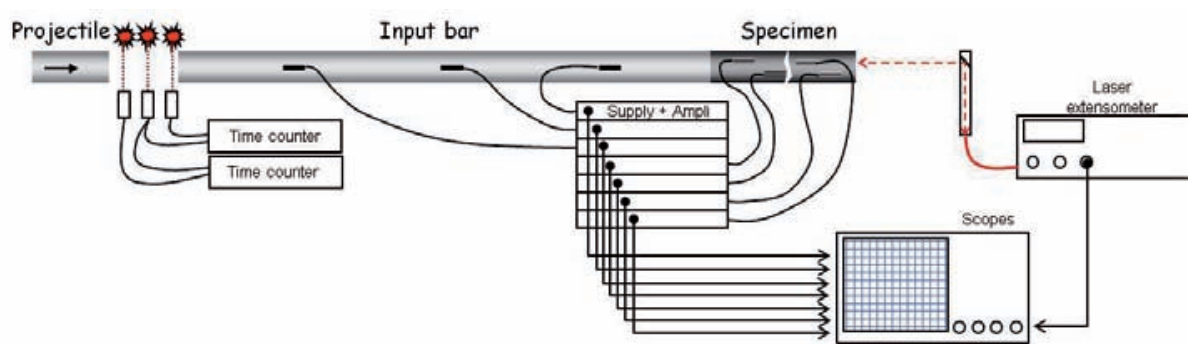

Fig. 1. Experimental configuration of the spalling test.

These tests are unu sual because the mechanical eq uilibrium of $t$ he speci men is n ever reached during the experiment. In this study, the basic setup consists of a proj ectile and a Ho pkinson bar diameter $46 \mathrm{~mm}$ and length respectively 75 an d $1200 \mathrm{~mm}$ made of aluminium alloy to reduce the impedance mismatch with concrete. Several strain gauges are placed on the input bar to characterize the incident loading. Other gauges are glued directly on the specimen. Linked to the high frequency scope (Bandwidth: $500 \mathrm{MHz}$, recordin $\mathrm{g}$ frequency: $10 \mathrm{MS} / \mathrm{s}$ ), they allow recording the stress field evolution during the spalling test. Moreover, a la ser extensometer (Bandwidth: $1.5 \mathrm{MHz}$ ) points out the rear face of the tested specimen to $g$ et the free velocity signal. From this last experimental data the dynamic te nsile stre ngth $\sigma_{d y n}$ is ide ntified using the li near acou stic ap proximation of Novikov [13]:

$$
\sigma_{d y n}=1 / 2 \rho C_{0} \Delta V_{p b}
$$

where $\rho$ is the density, $C_{0}$ is the one-dimensional wave velocity and $\Delta V_{p b}$ is the pullback velocity, i.e. the diff erence bet ween the maximum v elocity reac hed at th e rear $\mathrm{f}$ ace and th e reb ound $\mathrm{v}$ alue of velocity (cf. Fig. 2). 


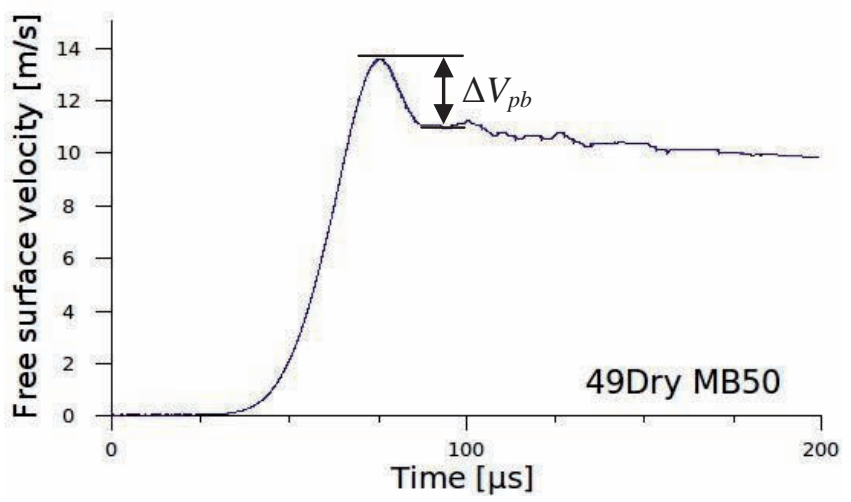

Fig. 2. Free surface velocity recording with the laser extensometer - 49Dry test performed on MB50 micro-concrete.

The experim ental ca mpaign w as co nducted on dry and wet speci mens of concrete and $\mathrm{m}$ icroconcrete. During the experiments, an ultra-high speed camera with a maximum frame rate of $1 \mathrm{Mfps}$ has been used to study the fragmentation kinetics in both concretes. After the test, frames have been post-processed with the Correli Q4 data image correlation (DIC) software (LMT-Cachan) to perform quantitative measurements of th e di splacement field. An example of spalling test perform ed on MB50 micro-concrete specimen is presen ted in Figure 3a. The corresponding field of displace ment (in pixels) obtain ed by using Correli Q4 is sh own. No crack s are v isible on the specimen at this point. Nevertheless the correlation results reveal several discontinuities of displace ment. In Figure $3 \mathrm{~b}$ the displace ment ded uced from the velocity signal of laser ex tensometers is co mpared to the average $v$ alue of fragments, time $t=0$ co rresponding to th e begi nning of ten sile stres ses in the concrete specimen according to strain gauges. A good ag reement between these two techniques is observed. This technique has been applied to spalling test performed on R30A7. Figure 3c presents the displace ment field and $\mathrm{s}$ hows that the detected discontinuities correspond to $\mathrm{f}$ racture planes of the specimen. Thus the DIC method allows detecting early the damage in the specimen and carrying out an accurate evaluation of the strain field.

The spalling strength sensitivity to the strain rate of the micro-concrete and the concrete has been studied bet ween 30 a nd 150/s by v arying the i mpact velocity of the projectile. Dynamic tensile strengths obtained are plotted in Figure 4. The trends of the MB50 micro-concrete are similar to data of $\mathrm{R} 30 \mathrm{~A} 7$ con crete. $\mathrm{T}$ his obs ervation s upports the hy pothesis that a ggregate s ize has a li mited influence even at high strain rates.
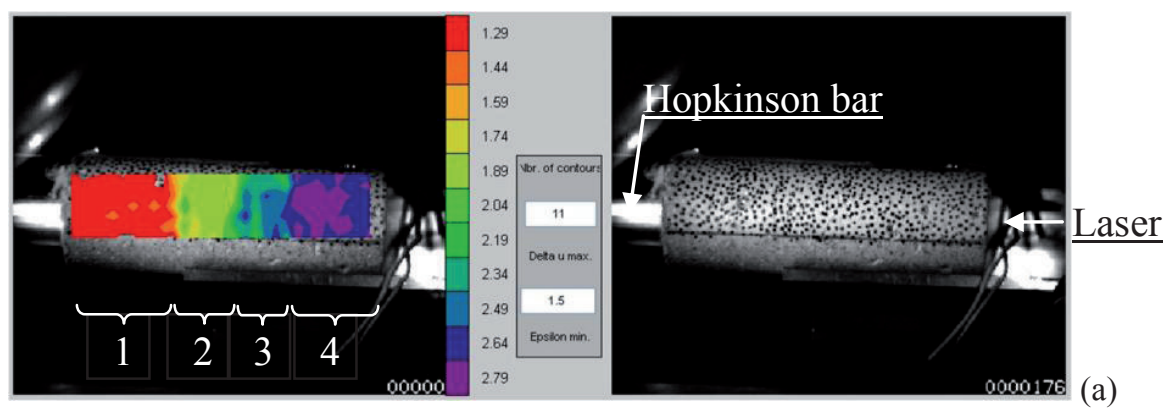

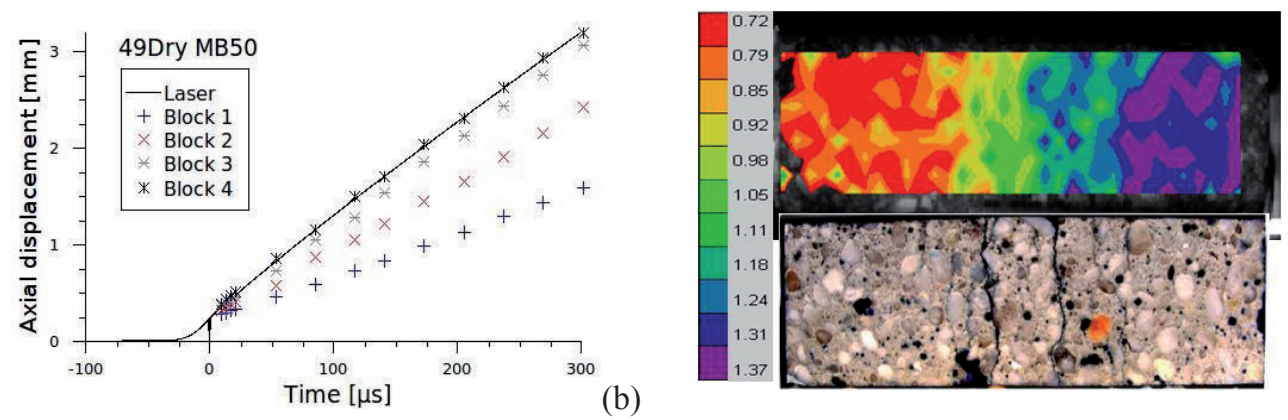

(b)

(c)

Fig. 3. (a) Displacement field measured by Digital Image Correlation (scale in pixels) in a spalling test (MB50 specimen - 49Dry test), (b) Comparison of axial displacements deduced from DIC and from the laser extensometer signal (MB50 49Dry test), (c) Comparison of the displacement field (in pixels) and the post mortem cracking pattern of a R30A7 specimen (23Wet test).

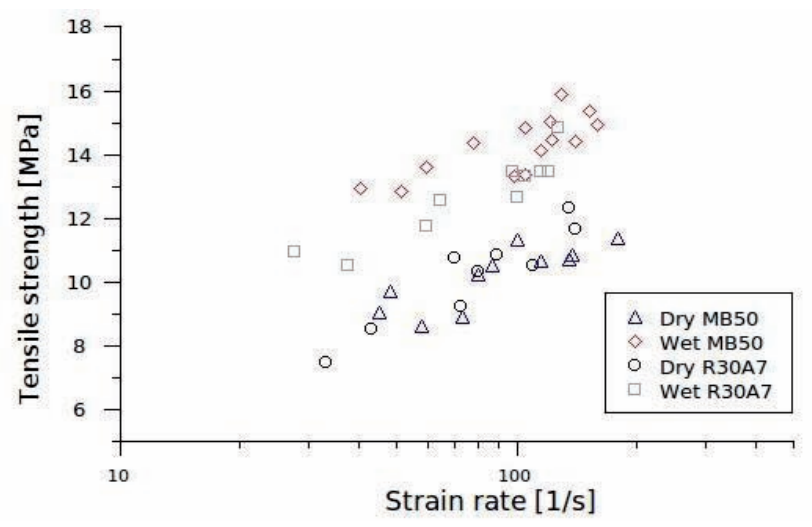

Fig. 4. Dynamic tensile strength of the MB50 and the R30A7 concretes obtained from spalling tests.

\section{Damage under impact: edge-on impact test}

\subsection{Principle of the EOI experiment}

A localized dynamic loading on a concrete structure like a ballistic i mpact or a deto nation leads to characteristic outcomes. In order to i mprove the understanding of the fragmentation of concrete, the edge-on impact test was developed at the Ernst Mach Institute - Germany [14] and at the Centre Technique d'Arcueil - France [15]. This experimental technique has been designed to reproduce in a two-dimensional configuration the loading of a ballistic impact. The growth of damage is visualized using a high speed camera at the surface of the target. The principle of the experiment consists in projecting a stri ker on the edge of a plate composed of the material to be test ed. The loading wave generates a high co mpressive zo ne n ear the i mpacted zo ne and th en spreads i nto the target. The radial displacement of matter induced by the passage of the incident pulse generates dynamic tensile stresses in the hoop directio $\mathrm{n}$ th at result $\mathrm{i} \mathrm{n}$ intense $\mathrm{f}$ ragmentation composed of radial crack $\mathrm{s}$. Ceramics [14], glasses [15], ultra-high strength concrete [16] have been tested with ed ge-on impact tests. In th is st udy, several tests were performed on dry and wet specimens of the M B50 micro- 
concrete and of the R30A7 concrete in the so-called sarco phagus configuration: concrete plates are encapsulated in an aluminium box that keeps fragments close to th eir original position (cf. Fig. 5). After the test, a coloured hyperfluid resin is injected to highlight the damage pattern. Additionally, a dynamic confinement system [5] was used to locally increase the pressure in the projectile-specimen contact zo ne at the begi nning of $t$ he load ing, red ucing t his way t he co mpressive da mage a nd improving the spread of the incident wave in the tile (see Fig . 5).

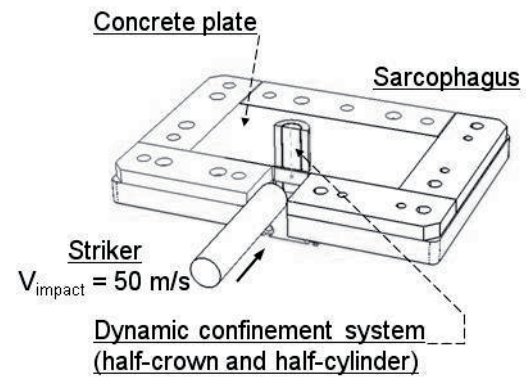

Fig. 5. Experimental configuration of the EOI test.

\subsection{Experiments conducted on the MB50 micro-concrete}

Several numerical simulations were conducted to determine a test configuration (impact velocity and length of projectile) that creates a dy namic tensile loading in the concrete target comparable to that observed in spalling tests. It was established that a projectile $22.5 \mathrm{~mm}$ in diameter and $100 \mathrm{~mm}$ in length with an initial velocity of $50 \mathrm{~m} / \mathrm{s}$ may generate a tensile strain rate of about $150 / \mathrm{s} \mathrm{at} 50 \mathrm{~mm}$ from the impact spot [17].

First EOI tests were carried out on MB50 micro-concrete plates of $200 \mathrm{x} 120 \mathrm{x} 15 \mathrm{~mm}^{3}$. The specimens were infiltrated post mortem and polis hed to reveal the cracks. The results obtain ed on dry and wet specimens are reported in Figure 6. It can be remarked that a higher cracking density has developed during the te st performed on a dr y specimen. Moreover, the existing cracks in the wet target see $\mathrm{m} t$ hinner a nd more clo sed. Con sequently, free water i $\mathrm{n} t$ he micro-concrete sh ows a significant i nfluence on the damage pattern. P erforming these test s o $\mathrm{n}$ co ncrete R30 A7 al lows determining the influence of aggregate size on damages due to an impact loading.
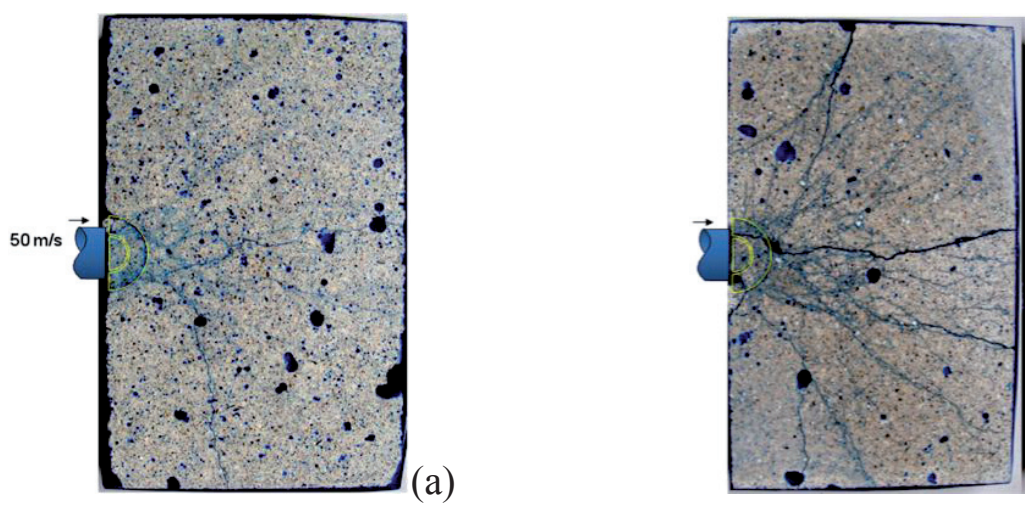

(b)

Fig. 6. Cracking pattern of EOI tests performed on (a) a wet MB50 tile and (b) a dry MB50 tile. 


\subsection{Experiments conducted on the R30A7 concrete}

Standard c oncretes in clude generally ag gregates a t t he c entimetre sca le. Co nsequently, it is necessary to evaluate the influence of aggregate size on the dynamic response of concrete. EOI tests were performed on dry and wet specimens of R30A7 concrete keeping the previous parameters: the projectile has a d iameter of $22.5 \mathrm{~mm}$ and a length of $100 \mathrm{~mm}$ and is projected on to the target at a speed of $50 \mathrm{~m} / \mathrm{s}$. Like for the MB50 micro-concrete, the specimens were infiltrated post-mortem and polished to bring out the cracks. The damage patterns are presented Figure 7. Again, the influence of free water is obvious: the damage is much more pronounced in the dry tile. In the same way as the MB50 micro-concrete, an int ense cracking develo ped n ear the i mpacted area. Farth er, many long radial cracks are obs erved. Oppositely, in the wet tile the cracking network is less developed and cracks are hardly $\mathrm{v}$ isible. $\mathrm{B}$ esides, on e can se e th at few ag gregates are brok en: crack $\mathrm{s} \mathrm{h}$ ave circumvented the inclusions during their propagation.
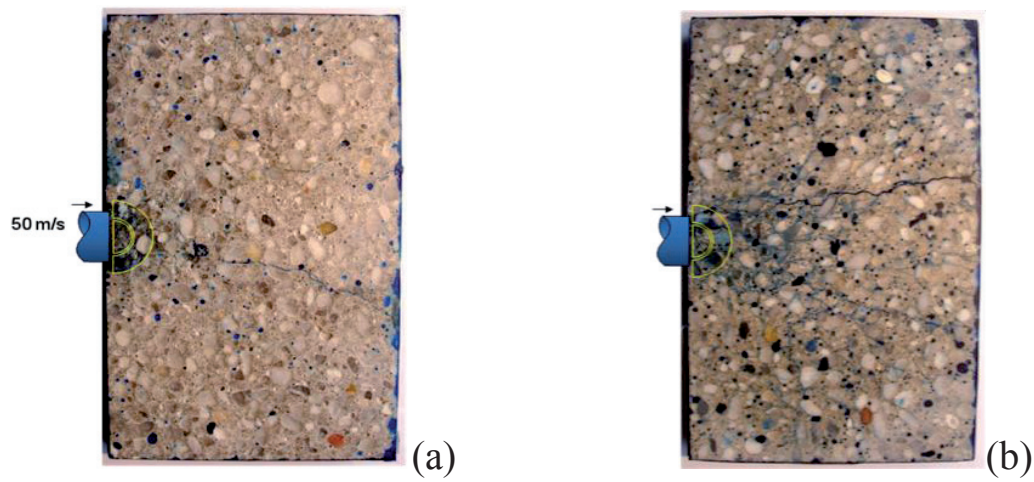

Fig. 7. Cracking pattern of EOI tests performed on (a) a wet R30A7 tile and (b) a dry R30A7 tile.

\subsection{Maximum aggregate size influence on damage under impact}

Despite si gnificant diff erences in ter ms of microstructure bet ween MB50 micro-concrete and R30A7 co ncrete, da mage patterns produ ced b y i mpact ar e v ery s imilar: i n wet co nditions small cracks and li mited crack ope ning are $\mathrm{n}$ oted, whereas in d ry co nditions a pron ounced damage is observed. It is i nteresting to $\mathrm{n}$ ote that few a ggregates ar e brok en, crack ing being pre dominantly inter-granular: thus the matrix behaviour seems to drive the dynamic fragmentation. Consequently, the maximum size of ag gregates ap pears to play a limited role on the cracking pattern of samples subjected to im pact. Otherwise, the free water ap pears as a $m$ ore important factor. The differences between dry and wet samples are more pronounced than between micro-concrete and concrete.

\section{Conclusions}

To assess the importance of aggregate size on the tensile behaviour of concrete subjected to high speed dynamic loading, two experimental methods have been used. On the one hand, a campaign of spalling tests has been co nducted on a standard concrete with a maximum aggregate size of $8 \mathrm{~mm}$ and a micro-concrete (maximum grain size: $2 \mathrm{~mm}$ ). For both materials these experiments have been carried out on dry and wet specimens. The dynamic tensile tests performed between 30 an d 150/s showed very similar results for both concretes despite their difference of the microstructure size. The 


\section{EPJ Web of Conferences}

moisture has shown a great influence on the dynamic strength of both concretes. Moreover an ultrahigh speed ca mera has been used. The acqu ired frames have been post -processed with a Digital Image Correlation software. It allowed identifying the fracture planes at th e early stage of damage and evaluating finely the strain field evolution during the spalling test. On the other hand, EOI tests have been co nducted to asse ss the influence of aggregate size on the da mage pattern of concrete when subjected to an impact loading. Similar trends than in spalling tests have been observed in both concretes: $t$ he crack ing is predominantly i nter-granular. Agai $n$, th e free water changes more significantly the da mage pattern. These observ ations show th at the res ults obtai ned from d ynamic tensile experiments on a micro-concrete, easier to test, can be transposed to a standard concrete.

\section{References}

1. F. Toutlemonde, Ph.D. thesis, LCPC, Paris, France (1994)

2. J.R. Klepaczko, A. Brara, Int. J. Impact Engrg. 25 (2001)

3. H. Schuler, C. Mayrhofer, K. Thoma, Int. J. Impact Engrg. 32 (2006)

4. J. Weerheijm, JCAM. Van Doormaal, Int. J. Impact Engrg. 34 (2007)

5. P. Forquin, Ph.D. thesis, LMT Cachan, France (2003)

6. G. Bernier, JM. Dalle, Report, Science Pratique S.A (1998)

7. G. Gary, J.R. Klepaczko, GRECO Geomaterial scientific report (1992)

8. E. Buzaud, Report Centre d'Etudes de Gramat (1998)

9. P. Forquin, G. Gary, F. Gatuingt, Int. J. Impact Engrg 35 (2008)

10. P. Forquin, K. Safa, G. Gary, Cement Con. Res., DOI: 10.1016/j.cemconres.2009.09.024 (2009)

11. X.H. Vu, Ph.D. thesis, L3S-R, Grenoble, France (2007)

12. T. Gabet, Ph.D. thesis, L3S-R, Grenoble, France (2006)

13. S.A. Novikov, II. Divnov, A.G. Ivanov, Fizika Metallov i Metallovedeniye 21 (1966)

14. E. Strassburger, H. Senf, EMI Report (1994)

15. X. Brajer, P. Forquin, R. Gy, F. Hild, J Non Crystal Solids, 316 (2003)

16. P. Forquin, F. Hild, J. Eng. Mech., 134 (2008)

17. P. Forquin, B. Erzar, Int. J. Fracture, DOI: 10.1007/s10704-009-9419-3 (2009) 